\title{
Acid-base properties of aluminosilicates from rice husk and straw
}

\author{
Olga D. Arefieva ${ }^{1,2} \cdot$ Polina D. Pirogovskaya $^{1,2} \cdot$ Alexander E. Panasenko $^{1} \cdot$ Ludmila A. Zemnukhova $^{1}$
}

Received: 8 February 2020 / Accepted: 8 April 2020 / Published online: 13 April 2020

(c) Springer Nature Switzerland AG 2020

\begin{abstract}
We obtained aluminosilicates of sodium and potassium from alkaline hydrolysate of rice straw and husk. Chemical, phase composition of the samples was determined, and nature of the functional groups was studied. We presented results of studying acid-base properties of aluminosilicates' surface by $\mathrm{pH}$-metry and Hammett methods. We built distribution curves of a number of acid-base centers of the samples from $\mathrm{pK}_{\mathrm{a}}$ indicators. It was found that the surface of the asprepared aluminosilicates is characterized by a wider spectrum of Bronsted acid centers $\left(p K_{a}+2.5 ;+3.46 ;+6.4\right)$, presence of Lewis acid centers $\left(p K_{a}+16.8\right)$ and main Bronsted centers $\left(p K_{a}+9.45\right)$. The largest number of Lewis acid centers was recorded on the surface of sodium aluminosilicates with a narrow ratio of $\mathrm{Al}_{2} \mathrm{O}_{3}: \mathrm{SiO}_{2}=1: 2$, the smallest—on the surface of potassium aluminosilicate with a wide ratio of $\mathrm{Al}_{2} \mathrm{O}_{3}: \mathrm{SiO}_{2}=1: 5$. The maximum number of Bronsted acid centers was present on the surface of sodium aluminosilicates from rice straw, the minimum —on the surface of potassium aluminosilicate with the amount of $\mathrm{SiO}_{2}$ equal to $41 \%$.
\end{abstract}

Keywords Rice husk · Rice straw · Aluminosilicates · Acid-base properties

\section{Introduction}

Aluminosilicates that make up a vast group of silicates are formed by silicon dioxide (silica) and oxides of other elements. Spectrum of chemical composition of silicates is quite wide [1]. Natural aluminosilicates include feldspars, clay minerals, vermiculites, nepheline and others. The most significant disadvantages of natural aluminosilicates are the inconsistency of the chemical and phase composition within the same deposit. The advantages of the as-prepared aluminosilicates are their constant composition and lower impurity content. Chemical and phase composition of the as-prepared aluminosilicates are increasingly determined by the feedstock and production procedure [2].

Main source of obtaining silicon-containing materials, including the synthesis of aluminosilicates, are mineral forms, for example, silica sand, silica-containing rocks or waste from various industries [3]. Silica plants, in particular, rice production waste, can be an alternative source of silica for producing aluminosilicates [4].

Having high adsorption, ion exchange and catalytic properties, aluminosilicates are more and more used in various industries, agriculture and science [5]. Both natural and the as-prepared aluminosilicates are mainly used as sorbents, carriers of catalysts, ion-exchange materials and are widely used for purifying industrial water from ammonia, heavy metal cations, organic substances, microorganisms, and for desalination of sea water [6-8].

It is necessary to have a set of experimental data characterizing properties of the surface (composition and structure of surface compounds, physicochemical characteristics) to understand nature and mechanism of processes occurring on the surface of a solid substance and use the results to solve practical problems [9]. One of the main characteristics that most accurately reflects surface reactivity in donor-acceptor interactions is acid-base properties which show almost all fundamental parameters and

Olga D. Arefieva, arefeva.od@dvfu.ru | 'Institute of Chemistry Far-Eastern Branch, Russian Academy of Sciences, 159 Stoletiya St., Vladivostok, Russian Federation 690022. 2 Far Eastern Federal University, 8 Suhanova St., Vladivostok, Russian Federation 690950. 
functional properties of a solid substance [10]. Knowing the composition and content of active centers makes it possible to predict the reactivity and sorption capacity of the surface with respect to pollutants of various nature. The aim of this work is to study acid-base properties of the surface of aluminosilicates from rice husk and straw.

\section{Materials and methods}

\subsection{Objects and instrumental methods of research}

Objects of the study were samples of aluminosilicates obtained from rice straw (Oryza sativa) of Far Eastern breeding varieties (Primorsky Krai, Timiryazevsky village), rice husk selected in Heilongjiang Province (People's Republic of China). Potassium aluminosilicate (N5) synthesized from reagents [11] was used as a comparison sample.

$\mathrm{X}$-ray phase analysis of the samples was studied on a D8 Advance diffractometer (Bruker, Germany) in Cu $K_{a^{-}}$ radiation. The phases were identified using the EVA program, PDF-2 powder data bank. IR absorption spectra were recorded in the region of $400-4000 \mathrm{~cm}^{-1}$ in potassium bromide on a Vertex 70 Fourier spectrometer (Bruker, Germany). Elemental analysis was performed by energy dispersive X-ray fluorescence spectroscopy on an EDX 800 HS spectrometer (Shimadzu, Japan). Concentration of elements was calculated using a calibration graph. Specific surface value $\left(\mathrm{S}_{\text {sp. }}\right)$ was determined by nitrogen adsorption on an ASAP 2020 analyzer (MICROMERITICS Instrument Corporation, USA) and calculated by BET method (Brunauer-Emmett-Teller), and pore size distribution and average pore diameter $d$ were determined by $\mathrm{BJH}$ method (Barrett-Joyner-Hallenda). Loss by roasting was determined by a change in mass of the sample after calcination at $900{ }^{\circ} \mathrm{C}$, which allows to estimate the content of constituent water.

List of the samples of aluminosilicates N1-N5 and their characteristics are presented in Table 1.

The as-prepared samples of aluminosilicates (N1-N4) were obtained according to the procedure [12] from alkaline hydrolysates (1 M NaOH or $1 \mathrm{M} \mathrm{KOH}$ ) of rice straw (RS) and rice husk (RH) (mass ration solid to liquid was $1: 13$, temperature $90^{\circ} \mathrm{C}$, stirring for $60 \mathrm{~min}$ ). A saturated aqueous solution of aluminum sulfate $\mathrm{Al}_{2}\left(\mathrm{SO}_{4}\right)_{3} \cdot 18 \mathrm{H}_{2} \mathrm{O}$ was used as an aluminum source, which was added to the hydrolysate at a room temperature in the required amount, and the $p H$ of the reaction mixture was adjusted to 7 with hydrochloric acid solution.

\subsection{Study of acid-base surface properties}

\subsection{1 pH-metry method}

Acid-base properties of the surface of the aluminosilicates were studied by $\mathrm{pH}$-metry method, which allows to evaluate the integral acidity of the surface. The $\mathrm{pH}$ was measured on a SevenCompact pH-meter (Mettler Toledo, Switzerland) using $\mathrm{X}$-Lab software. For this purpose, $20 \mathrm{ml}$ of distilled water with $p H_{0}=6.4-7.6$ were added to the potentiometric cell. A glass electrode was placed into distilled water, and after stabilization of the potential, $0.2 \mathrm{~g}$ of the sample were added [13]. $\mathrm{pH}$ of the suspension after the sample contacted with water for 10-900 s was chosen as a parameter characterizing acid-base state of the surface [14].

\subsubsection{Hammett method}

To study distribution of surface centers by acid-base properties, we used Hammett method with 13 indicators with $p K_{a}$ values ranging from -0.29 to +16.80 [13].

Main solutions of indicators with $0.01 \%$ concentration were used in the work. Working solutions of indicators were prepared by diluting main solutions with distilled water by 5 times. Optical density in visible region was measured on UNICO-1201 spectrophotometer (United Products \& Instruments Inc., USA), and in the ultraviolet region, on UV-1800 spectrophotometer (Shimadzu, Japan). All determinations were performed at a wavelength corresponding to the absorption maximum.

Table 1 Raw materials, number of aluminosilicate samples and their characteristics

\begin{tabular}{|c|c|c|c|c|c|}
\hline \multirow[t]{2}{*}{ Sample } & \multirow[t]{2}{*}{ Raw materials } & \multicolumn{4}{|c|}{ Characteristics of the samples } \\
\hline & & $\mathrm{X}$-ray phase analysis & $\begin{array}{l}\text { Loss by roasting } \\
\text { (\%) }\end{array}$ & $\mathrm{S}_{\mathrm{sp} .}\left(\mathrm{m}^{2} \mathrm{~g}^{-1}\right)$ & $\mathrm{d}(\mathrm{nm})$ \\
\hline N1 & Rice straw, breed_Khankaysky 429 & Amorphous & 28.4 & 69.0 & 19.0 \\
\hline N2 & Rice straw, breed-Priozersky 61 & & 29.4 & 68.0 & 18.5 \\
\hline N3 & Rice husk from People's Republic of China & & 29.0 & 115.9 & 16.1 \\
\hline N4 & & & 26.0 & 110.0 & 16.0 \\
\hline N5 & Reagents $\left(\mathrm{KOH}, \mathrm{AlCl}_{3} \cdot 6 \mathrm{H}_{2} \mathrm{O}, \mathrm{SiO}_{2} \cdot \mathrm{nH}_{2} \mathrm{O}\right)$ & Amorphous [11] & 19.2 & 105.0 & 3.7 \\
\hline
\end{tabular}


To determine a number of acid-base centers, three series of solutions were prepared:

- Indicator series. For photometry we took $5 \mathrm{ml}$ of working solution of indicator and added $5 \mathrm{ml}$ of distilled water. Optical density was measured relatively to distilled water and obtained $D_{0}$ value;

- Decanted water series. Sample weight $0.02 \mathrm{~g}$ was poured with $10 \mathrm{ml}$ of water. Resulting suspension was stirred for $30 \mathrm{~min}$. Then, solution was decanted, $5 \mathrm{ml}$ of solution were taken, optical density was measured relatively to distilled water and $D_{1}$ value was obtained;

- Test sample series. Sample weight $0.02 \mathrm{~g}$ was poured with $5 \mathrm{ml}$ of indicator working solution and $5 \mathrm{ml}$ of distilled water. Resulting suspension was stirred for $30 \mathrm{~min}$. Then solution was decanted, $5 \mathrm{ml}$ of solution were taken, absorbance was measured relatively to distilled water and $D_{2}$ value was obtained.

A number of centers of a given acid strength $\left(q_{p k a}\right.$ $\mathrm{mmol} \cdot \mathrm{g}^{-1}$ ) equivalent to the amount of adsorbed indicator was calculated by the formula:

$q_{p K a}=\frac{C_{i n d} \times V_{\text {ind }}}{D_{0}} \times\left[\frac{\left|D_{0}-D_{1}\right|}{\alpha_{1}} \pm \frac{\left|D_{0}-D_{2}\right|}{\alpha_{2}}\right]$,

where $C_{\text {ind }}$ and $V_{\text {ind }}$ are concentration and volume of an indicator; $a_{1}$ and $a_{2}$ are sample weights while measuring $D_{1}$ and $D_{2}$; sign "-" corresponds to unidirectional change of $D_{1}$ and $D_{2}$ relatively to $D_{0}$, sign " + "to multidirectional.

Distribution curves of adsorption acid centers on the surface of the samples were plotted in the coordinates $q_{p K a}-p K_{a}$. Surface acidity function $\left(H_{0}\right)$ of the sorbents was calculated by the formula:

$H_{0}=\frac{\sum p K_{a} \times q p K_{a}}{\sum q p K_{a}}$

Table 2 Content of the main components in aluminosilicates and their molar ratio

\section{Results and discussion}

\subsection{Composition and structure of the samples}

Content of the main components in aluminosilicates and their molar ratio are shown in Table 2. Aluminosilicates synthesized from $\mathrm{RH}$ and $\mathrm{RS}$ correspond to the formula $\mathrm{M}_{\mathrm{x}} \mathrm{Al}_{\mathrm{y}} \mathrm{Si}_{\mathrm{z}} \mathrm{O}_{\mathrm{n}} \cdot \mathrm{m} \cdot \mathrm{H}_{2} \mathrm{O}$, where $\mathrm{M}=\mathrm{Na}((\mathrm{N} 1-\mathrm{N} 3)$ and $\mathrm{K}(\mathrm{N} 4)$. Presence of potassium in sodium aluminosilicate samples is explained by its presence in plant tissues [15]. Comparison sample (N5) has composition $\mathrm{KAISi}_{3} \mathrm{O}_{8} \cdot 1,5 \mathrm{H}_{2} \mathrm{O}$ [11].

According to the results of $\mathrm{X}$-ray phase analysis, samples $\mathrm{N} 1-\mathrm{N} 5$ are in an X-ray amorphous state.

All the studied samples of aluminosilicates have a similar type of the FTIR spectra. In the FTIR spectra of the asprepared samples (N1-N5), one can observe absorption bands that correspond to stretching and deformation vibrations of $\mathrm{O}-\mathrm{H}$ bonds of adsorbed and bound water with maxima in regions $3431 \mathrm{~cm}^{-1}$ and $1641 \mathrm{~cm}^{-1}$. The spectra of the samples contain absorption bands in the region $1014 \mathrm{~cm}^{-1}, 588 \mathrm{~cm}^{-1}$ and $442 \mathrm{~cm}^{-1}$, corresponding to vibrations of siloxane bonds. Specific to aluminosilicates is the presence of a band that is specific to aluminosilicates at $700 \mathrm{~cm}-1$, corresponding to the vibrations of the $\mathrm{Al}-\mathrm{O}-\mathrm{Si}$ bonds, as well as the position of the absorption band at $1014 \mathrm{~cm}^{-1}$, corresponding to the asymmetric stretching vibrations of the $\mathrm{Si}-\mathrm{O}$ bond. In aluminosilicate obtained from reagents (N5, Table 1), this band is shifted to the region of $1072 \mathrm{~cm}^{-1}$. The presence of a band in the FTIR spectrum in the region of $860 \mathrm{~cm}^{-1}$ indicates the presence of silanol groups $\mathrm{Si}-\mathrm{OH}$ (Fig. 1) [16].

\subsection{Acid-base surface properties}

\subsection{1 pH-metry method}

$\mathrm{pH}$-metry method allows to evaluate an integrated acidity of the surface of the samples. Determining factor in measuring $\mathrm{pH}$ of the medium at the beginning is the process of interaction of water molecules with the surface of the sample. An increase in the $\mathrm{pH}$ of the suspensions at first seconds indicates the presence on the surface of

\begin{tabular}{|c|c|c|c|c|c|c|c|}
\hline \multirow[t]{2}{*}{ Sample } & \multicolumn{4}{|c|}{ Content (mass\%) } & \multicolumn{3}{|c|}{ Molar ratio } \\
\hline & $\mathrm{Na}_{2} \mathrm{O}$ & $\mathrm{K}_{2} \mathrm{O}$ & $\mathrm{Al}_{2} \mathrm{O}_{3}$ & $\mathrm{SiO}_{2}$ & $\mathrm{M}_{2} \mathrm{O}$ & $\mathrm{Al}_{2} \mathrm{O}_{3}$ & $\mathrm{SiO}_{2}$ \\
\hline N1 & 9.8 & 1.4 & 27.9 & 30.2 & 0.63 & 1 & 1.84 \\
\hline N2 & 7.3 & 1.6 & 30.9 & 30.3 & 0.44 & 1 & 1.67 \\
\hline N3 & 14.1 & 0.4 & 31.1 & 37.2 & 0.76 & 1 & 2.03 \\
\hline N4 & - & 17.4 & 39.1 & 41.4 & 0.48 & 1 & 1.80 \\
\hline N5 & - & 12.2 & 19.2 & 56.0 & 0.69 & 1 & 4.96 \\
\hline
\end{tabular}




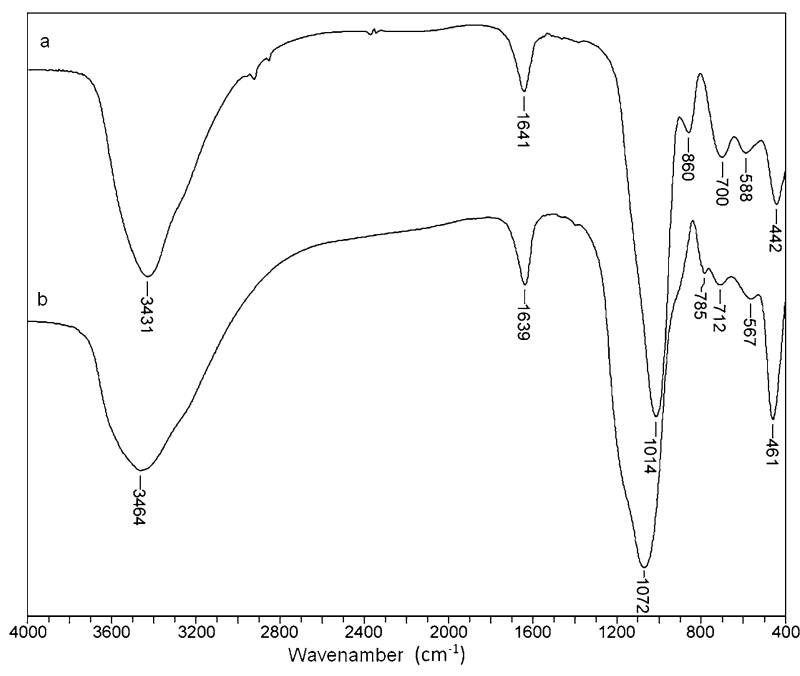

Fig. 1 The FTIR spectra of the as-prepared aluminosilicates: a sodium aluminosilicate from RS; $\boldsymbol{b}$ aluminosilicate $\mathrm{KAISi}_{3} \mathrm{O}_{8} \cdot 1,5 \mathrm{H}_{2} \mathrm{O}$

aluminosilicates of the main Lewis centers on which water is sorbed by the main mechanism (Fig. 2). When samples are suspended, surface hydration occurs and Lewis main centers turn into Bronsted acid centers, while hydroxy groups go into solution, increasing $\mathrm{pH}$ value. According to [17], Lewis main centers in aluminosilicates are oxygen in $\mathrm{Si}-\mathrm{O}-\mathrm{Si}$ bridge groups containing $\mathrm{Al}, \mathrm{K}$, and $\mathrm{Na}$ atoms. Adsorption-desorption equilibrium is reached in 60-90 s. Steady-state $\mathrm{pH}$ value of the samples obtained from RS and $\mathrm{RH}(\mathrm{N} 1-\mathrm{N} 4$, Table 1) indicates basic state of the surface ( $p H$ 9.5-10.0). More alkaline media of the solution of the samples $\mathrm{N} 1$ and $\mathrm{N} 3$ is associated with a large number of alkali metal cations in comparison with samples $\mathrm{N} 2$ and N4 (Table 2). Aluminosilicate obtained from reagents (N5, Table 1) has a weakly basic surface state $(p H 7.5)$ due to a high ratio of $\mathrm{M}_{2} \mathrm{O}: \mathrm{SiO}_{2}$ (Table 2).

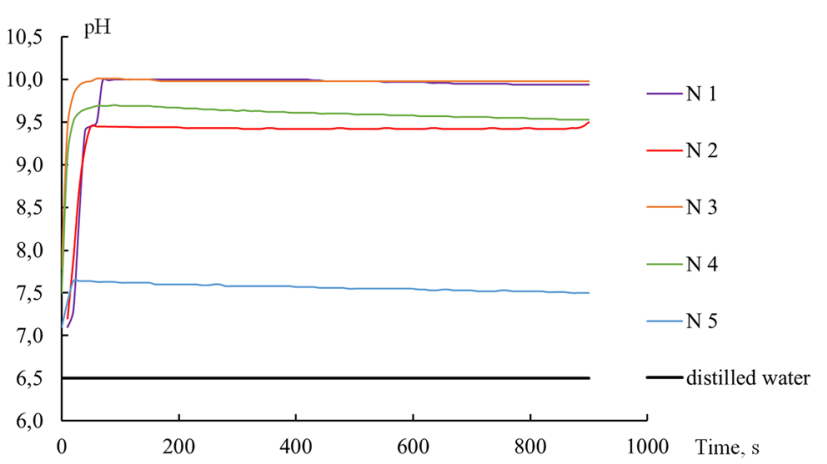

Fig. $2 \mathrm{pH}$ change curves of aqueous suspensions of the as-prepared aluminosilicates (samples N1-N5)

\subsubsection{Hammett method}

To study distribution of the surface centers by acid-base properties, we used Hammett method which is based on selective adsorption of acid-base indicators with specified values of the acidity constants of indicators $\left(p K_{a}\right)$. The result is a spectrum of distribution of indicator adsorption centers $\left(q, \mathrm{mmol} \mathrm{I}^{-1}\right)$ on the surface as a function of $p K_{a}$ ( $p K_{a}$ spectrum). In such spectra, acid centers are located above the neutral point $\left(p K_{a}=7\right)$ on which base indicators are adsorbed with $p K_{a}<7$. Below there are base centers on which occurs acid indicator adsorption $\left(p K_{a}>7\right)$. At $p K_{a}=7$ adsorbate molecules equally possess both acidic and basic properties [18].

Figure 3 shows distribution curves of adsorption centers of Hammett indicators on the surface of aluminosilicates obtained from alkaline hydrolysate of $\mathrm{RH}$ and $\mathrm{RS}$, and from chemically pure reagents. Distribution of acid-base centers on the surface is nonmonotonic and heterogeneous, and manifests itself in discreteness with a fairly clear differentiation of sorption bands with maxima of different intensities corresponding to a certain $p K_{a}$ value. The spectra are similar to each other, there are 4 main bands that describe active centers, such as Bronsted acid $\left(p K_{a}+2.5\right.$ and 3.46), weak acid $\left(p K_{a}+6.4\right)$, main $\left(p K_{a}+9.45\right)$ and Lewis acid $\left(p K_{a}+16.8\right)$.

According to [10], Lewis type acid centers $\left(p K_{a}+16.80\right)$ on the surface of aluminosilicates are formed upon isomorphic substitution of tetravalent silicon in silicon dioxide lattice by trivalent aluminum atoms. Under such conditions, aluminum atom tends to obtain a pair of electrons to fill its $p$-orbital. Samples N1-N4 are characterized by approximately the same ratio $\mathrm{Al}_{2} \mathrm{O}_{3}: \mathrm{SiO}_{2} \approx 1: 2$ (Table 2). The largest number of such centers is recorded in sodium aluminosilicates (N1-N3). On the surface of potassium aluminosilicate obtained from $\mathrm{RH}(\mathrm{N} 4)$ the

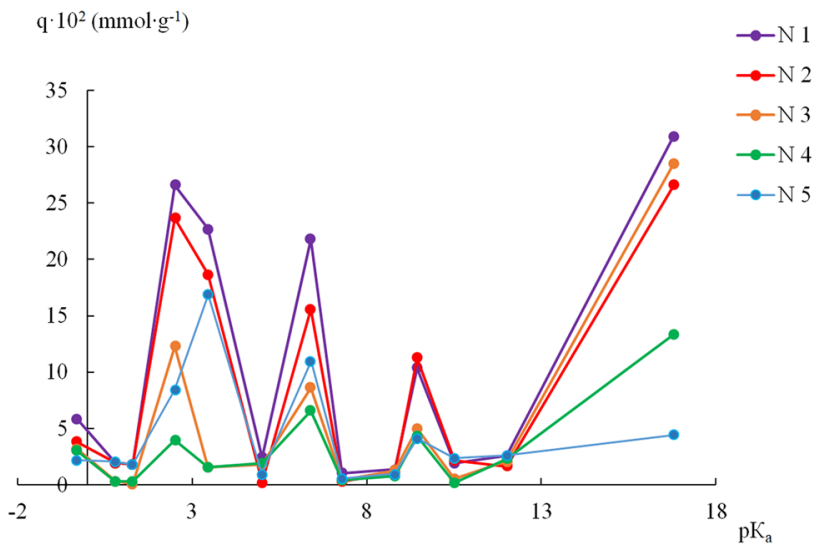

Fig. 3 Distribution of active centers on the surface of the as-prepared aluminosilicates (samples N1-N5) 
Table 3 Surface acidity function of aluminosilicates

\begin{tabular}{llllll}
\hline Sample & N1 & N2 & N3 & N4 & N5 \\
\hline Value & 7.51 & 7.67 & 8.88 & 8.42 & 5.65 \\
\hline
\end{tabular}

number of acid centers is less, because according to [10] an increase in the radius of cation to a decrease in the intensity of Lewis acid centers. Potassium aluminosilicate obtained from reagents (N5) with a high ratio of $\mathrm{Al}_{2} \mathrm{O}_{3}: \mathrm{SiO}_{2}=1: 5$ contains the least amount of Lewis acids.

While interacting with water occurs formation of Bronsted acid centers expressed by $\mathrm{Si}-\mathrm{OH}$ groups $\left(p K_{a}+2.5\right.$ and 3.46) and weakly acidic Bronsted centers $\left(p K_{a}+6.4\right)$ formed by $\mathrm{Al}-\mathrm{OH}$ groups. The number of Bronsted acid centers is also larger on the surface of sodium samples $(\mathrm{N} 1, \mathrm{~N} 2)$ obtained from RS. The surface of sodium aluminosilicate obtained from $\mathrm{RH}$ is characterized by a lower amount of Bronsted acids in comparison with similar samples from RS. Such a distribution of centers is probably due to the fact that $\mathrm{RH}$ contains less impurities of alkaline-earth metals compared to RS [19].

It should be noted that the Bronsted acidity in aluminosilicates depends on $\mathrm{SiO}_{2}$ content and reaches its maximum value at its $70 \%$ content [10]. From this point of view, a high content of Bronsted centers in sample N5 containing $56 \% \mathrm{SiO}_{2}$ is explained (Table 2). The minimum content of Bronsted acids is characterized by potassium aluminosilicate obtained from RS.

On the surface of the as-prepared samples (Fig. 2) there is a small number of the main Bronsted centers $\left(p K_{a}+9.45\right)$, the formation of which is associated with impurities of alkaline-earth metal oxides contained in RS and $\mathrm{RH}[19]$ which are represented by $\mathrm{Me}(\mathrm{OH})^{\delta-}$ groups.

The series for the number of centers of the Lewis and Bronsted acid centers can be represented:

Lewis acid centers- $\mathrm{N} 1 \approx \mathrm{N} 2 \approx \mathrm{N} 3>\mathrm{N} 4(\mathrm{~K})>\mathrm{N} 5(\mathrm{~K})$.

Bronsted acid centers-N1 $\approx \mathrm{N} 2>\mathrm{N} 5\left(\mathrm{~K}, 56 \% \mathrm{SiO}_{2}\right)>\mathrm{N} 3$

$(\mathrm{RH})>\mathrm{N} 4(\mathrm{~K}, \mathrm{RH})$.

Calculation of a number of adsorption centers made it possible to calculate Hammett acidity function $\left(\mathrm{H}_{0}\right)$ which numerically allows to express the proton donor properties through Bronsted acidity (Table 3 ).

Table 3 shows that the surface of the as-prepared aluminosilicates is proton-acceptor, and the sample obtained from reagents are proton-donor.

\section{Conclusion}

Using Hammett indicator method and $\mathrm{pH}$-metry, acidbase properties of aluminosilicates from rice husk and straw. were studied. Using the $\mathrm{pH}$-metry method, it was shown that the as-prepared aluminosilicates have a basic surface state which depends on the ratio $\mathrm{M}_{2} \mathrm{O}: \mathrm{SiO}_{2}$.

It was found that surface properties of the as-prepared aluminosilicates are determined by the presence of centers in Bronsted acid $\left(p K_{a}+2.5\right.$ and 3.46), weakly acid $\left(p K_{a}+6.4\right)$ and main $\left(p K_{a}+9.45\right)$ regions, as well as in Lewis acid $\left(p K_{a}+16.8\right)$ region. The number of Lewis acid centers depends on two factors: the ratio of $\mathrm{Al}_{2} \mathrm{O}_{3}: \mathrm{SiO}_{2}$ and the nature of the monovalent cation and is almost independent of the nature of the raw material. The largest number of Lewis acid centers was recorded on the surface of sodium aluminosilicates with a narrow ratio of $\mathrm{Al}_{2} \mathrm{O}_{3}: \mathrm{SiO}_{2}=1: 2$, potassium aluminosilicate with the same ratio contains a smaller number of Lewis centers. The smallest was on the surface of potassium aluminosilicate obtained from reagents with a wide ratio of $\mathrm{Al}_{2} \mathrm{O}_{3}: \mathrm{SiO}_{2}=1: 5$. The number of Bronsted acid centers depends on several factors: the nature of raw materials and monovalent cation, the content of $\mathrm{SiO}_{2}$. The maximum number of such centers was present on the surface of sodium aluminosilicates from rice straw, the minimum-on the surface of potassium aluminosilicate with the amount of $\mathrm{SiO}_{2}$ equal to $41 \%$.

Acknowledgements The XRD, FT-IR techniques were obtained through Far Eastern Centre of Structural Analysis (FECSA) at the Institute of Chemistry FEB RAS (Vladivostok, Russian Federation). The authors are deeply acknowledged to colleagues from FECSA.

\section{Compliance with ethical standards}

Conflict of interest The authors declare that they have no conflict of interest.

\section{References}

1. Schultz MM (2001) Silicates in nature and human practice. In: Modern natural science: encyclopedia. Publishing House of the MAGISTR-PRESS, Moscow, pp 157-163

2. Yurkov V, Lankin SV, Baryshnikov SV, Kolesnikova LG, Rogulina LI, Serov AV (2004) Zeolites of the Amur region. Vestnik Far East Branch Russian Acad Sci 113:69-79

3. Melikyan AA, Melikyan SA, Melikyan AA, Babayan GG, Sychev VM (1998) Method for producing amorphous aluminosilicate for ultramarine. Russian Federation patent RU 2,106,303, 10 March 1998.

4. Ahmaruzzaman M, Gupta VK (2011) Rice husk and its ash as lowcost adsorbents in water and wastewater treatment. Ind Eng Chem Res 50:13589-13613. https://doi.org/10.1021/ie201477c 
5. Shoumkova A (2011) Zeolites for water and wastewater treatment: An overview. Res Bull Aust Inst High Energ Mater Spec Issue Glob Fresh Water Shortage 22:10-70

6. Sembiring S, Simanjuntak W, Manurung P, Asmi D, Low IM (2014) Synthesis and characterisation of gel-derived mullite precursors from rice husk silica. Ceram Int 40:7067-7072. https://doi. org/10.1016/j.ceramint.2013.12.038

7. Zakharov ON (2009) Extruded sorbents based on natural aluminosilicates for cleaning vegetable oils. Dissertation, Ivanovo, Russia

8. Bhavornthanayod C, Rungrojchaipon P (2009) Synthesis of zeolite a membrane from rice husk ash. J Met Mater Minerals 19:79-83

9. Ekimova IA, Minakova TS (2013) Acid-base and adsorption properties of the surface of oxides and fluorides of alkaline earth metals and magnesium. Polzunovsky Vestnik 1:67-71

10. Tanabe K (1973) Solid acids and bases. Mir, Moscow

11. Gordienko PS, Yarusova SB, Shabalin IA, Zheleznov VV, Zarubina NV, Bulanova SB (2014) Sorption properties of nanostructured potassium aluminosilicates. Radiochemistry 56:607-613. https ://doi.org/10.1134/S1066362214060058

12. Zemnukhova LA, Fedorishcheva GA, Tsoi EA, Arefieva OD (2014) Method for obtaining sodium or potassium aluminosilicates from silicon-containing plant raw materials. Russian Federation patent RU 2,014,113,045/05. 3 April 2014

13. Minakova TS (2007) Adsorption processes on the surface of solids: textbook. Publishing House of the Tomsk University, Tomsk

14. Ikonnikova KV, Ikonnikova LF, Minakova TS, Sarkisov YuS (2011) Theory and practice of $\mathrm{pH}$-metric determination of acid-base properties of the surface of solids: textbook. Tomsk Polytechnic University Publishing House, Tomsk

15. Zemnukhova LA, Polyakova NV, Fedorishcheva GA, Tsoi EA (2013) Elementary composition of amorphous silica samples of various origin. Chem Plant Raw Mater 1:209-214. https://doi. org/10.14258/jcprm.1301209

16. Panasenko AE, Borisova PD, Arefieva OD, Zemnukhova LA (2019) Aluminosilicates from rice straw: obtaining and sorption properties. Chem Plant Raw Mater 3:291-298. https://doi.org/10.14258 /jcprm.2019034278

17. Golubeva OYu (2016) Porous aluminosilicates with layered and frame structure: synthesis, properties and development of composite materials based on them for solving problems of medicine, ecology and catalysis. Dissertation. Institute of silicate chemistry n.a. I.V. Grebenshchikova, St. Petersburg, Russia

18. Plekhova EL, Lesishina YuO, Dmytruk AF (2010) Acid-basic centers of surface adsorption of porous carbon materials from plant raw materials. Scientific works of Donetsk national technical University. Ser Chem Chem Technol 162:155-159

19. Tsoi EA, Okara Al, Zemlyak KG (2011) About expediency of complex use of rice sown (Oryza sativa L.) of the zoned varieties of rice of Primorsky Krai. Technol Commodity Sci Innov Food Prod 10:12-17

Publisher's Note Springer Nature remains neutral with regard to jurisdictional claims in published maps and institutional affiliations. 